\title{
Analysis of the Factors Affecting College Students' Interest in Badminton Learning and Study on the Optimizing Strategies
}

\author{
Shouwen Wang \\ Heihe University \\ Heihe, China
}

\begin{abstract}
At present, with the continuous deepening of physical education reform, badminton becomes an indispensable event in sports. Increase of students' interest in learning it has become a topic concerned by people. This paper analyzes the reason for lack of interest in badminton of college students, and put forward strategies to deal with this situation to help college students improve the interest in badminton.
\end{abstract}

Keywords-badminton learning of college students; influence factors; optimizing strategy

\section{INTRODUCTION}

Badminton is not a traditional Chinese sports. Instead, it was introduced from the United Kingdom in last century. The competitive level of badminton in China has been in the forefront of the world and the development trend of badminton is getting better and better. At present, the concept of lifelong sports has been deeply rooted in the hearts of people, and badminton is also popular in people's lives. Badminton has become an indispensable event in college sports. In addition, playing badminton is very interesting and the value for health is high, which not only has significance in maintaining visual acuity and improving cardiopulmonary function, but also has significant effect in shaping beautiful body. Therefore, many college students like this sport very much. However, in many colleges and universities, with the carrying out of badminton courses, an awkward problem that students are not enthusiastic in badminton learning emerges. . The reasons for this phenomenon include not only students' own factors but also various factors such as schools and teachers.

\section{ANALYSIS OF THE FACTORS AfFECTING COLLEGE STUDENTS' INTEREST IN BADMINTON LEARNING}

\section{A. Teacher Factors}

In the teaching process of badminton in colleges and universities, teachers have the function of organizing sports and guiding sports, so their teaching level plays a decisive role in the students' learning outcomes and also affects the students' interest in learning badminton. Therefore, teachers must have excellent professional skills and badminton skills in order to convince students. They need to explain the necessary knowledge simply and clearly in actual teaching and accurately demonstrate the basic movements in order to improve students' interest in learning to a certain extent. On the other hand, the emotions of teachers when teaching also affect the students' learning mood. Generally speaking, the positive influential factors of the teacher in students' interest in learning badminton include the following aspects: firstly, teachers must have the organizing ability to concentrate the students and let students to participate in badminton practice by organizing competition or letting students who learn faster to help those who learn slower, so as to effectively improve the students' enthusiasm and participation; secondly, they can demonstrate the basic movements accurately for students to imitate. After grasping the correct learning methods, the difficulty of learning badminton is reduced, so students naturally have interest in badminton learning; besides, since teachers are objects that students can directly contact with and learn from, the teacher's precept and example are very important for students. Therefore, teachers must always pay attention to their own behavior, and think about the possible impact on the students before talking and doing things; finally, the comprehensive ability of teachers is also greatly related to the enthusiasm of students in learning badminton. For example, they should not only notice the differences in the badminton level of students in the teaching process, but also understand the differences in the personality of students. If they don'y pay close attention to personality of students, they may hurt some students in the teaching process, leading to getting half the result with twice the effort. On the contrary, if teachers usually observe students' personality traits, know which method can play the greatest incentive function for each student and have more patience and confidence, they are more likely to stimulate students' interest in learning [1].

\section{B. The Factors of Teaching Activities}

The good and bad of the organization of teaching activities can also have an impact on students' enthusiasm for learning badminton. The main reason is that badminton teaching activities are purposeful exercises on students' badminton technique and body flexibility to a certain extent, so badminton learning has enjoyment apart from scientificity and systematicness. Teachers tend to focus on explaining the theory and demonstrating actions when teaching students but 
neglect to adjust the classroom atmosphere, making the students have resistance in the badminton courses. Besides, they haven't rationally integrated the knowledge of other aspects related to badminton into badminton teaching, such as the benefits to body brought by badminton and content of sports aesthetics. They just simply demonstrate the essentials of badminton, which will make the classroom atmosphere rigidly suppressed [2].

\section{Students' Personal Factors}

There are great defects in education cause in China. Both students and parents pursue the principle of changing their destiny through knowledge. Many students, under enormous study pressure, have a very clear purpose for coming to school, namely moving toward a higher level. This is certainly right. In this society where education background determines everything, everybody wants to try their best to obtain a higher academic degree to lay the foundation for future work and life. It is okay to regard the achievement of academic work as the first priority, but we cannot neglect the physical exercise. After all, the body is the capital of revolution, and badminton is a good choice to take exercises. Some students consider themselves very clever and thinks them can learn very fast. Therefore, when their badminton level reaches a certain level, their interest in badminton will be weakened. In addition, some students have poor psychological quality, so when they experience some problems such as emotional trauma and problems caused by the trivialities in life, etc., their learning enthusiasm may be affected. There are many students lacking independence and the characteristics of facing the difficulty. They are too dependent on teacher and some students in the badminton learning process or want to give up when meeting learning bottleneck and can no longer focus on badminton learning, which have very bad effects on the training of interest in learning badminton. Some students have strong self-esteem, so the scold of teachers or derision of students is likely to give rise to their inferiority, making them lose the confidence in learning badminton.

\section{Anxiety in Training Activities}

Learning any knowledge requires concentration, so teachers must use more effective teaching methods to equip students with the necessary sport skills. In addition, interest is the best teacher and teachers should also develop students' interest as a driving force for teaching. The willpower of college students will also have a certain influence on badminton learning. Students may experience anxiety if they have great emotional fluctuation or badminton learning pressure from teachers. Only by creating a relaxed and lively learning environment can they allow students to effectively enhance the interest in learning. How to control students' mentality is the aspect that requires teachers' long-term efforts [3].

\section{STRATEGY FOR IMPROVING COLLEGE STUDENTS' INTEREST IN BADMINTON LEARNING}

\section{A. To Make Full Use of Online Teaching Advantages}

Badminton teaching in colleges and universities do not necessarily have to be taught by teachers hand by hand traditionally. They can also make full use of the advantages of the current era in badminton teaching of colleges and universities, produce courseware to teach badminton, and extend teaching under the conditions of basic study. Students can also copy courseware according to their needs, to meet their needs of previewing before class and after-school review. Even there are some content that they did not understand in class, they can figure out the knowledge after class by finding out relevant information based on courseware or ask teachers and students.

\section{B. To Combine Badminton Theory with Practice}

Regardless of the teaching of culture education or physical education, it is not easy to combine theory with practice in teaching and there is always a certain transition period. But once you do it, students' understanding of badminton knowledge can become more extensive. For example, in badminton doubles match teaching, because the doubles rules are complicated and boring, students will be at a loss in the practice process even if they remember the rules merely through rote memorization, let alone flexible application. However, direct on-site teaching enables students to personally experience the atmosphere of doubles and teachers' instruction allow them to use their bodies to memorize the feeling and rules of doubles, which plays a positive role in improving students' badminton skills and learning interests [4].

\section{The Change of Concept and Improvement of Understanding}

As a physical education teacher of college students, only when he insists that badminton learning is as important as cultural studies can he use his insistence to influence the people around, especially leaders and students who only value cultural education. Only by letting the leaders to pay attention to badminton learning, can relevant funds be timely replenishment; only when students recognize the importance of learning badminton, and change the concept of badminton can they accept badminton learning from the heart, and become interested in it.

\section{Improvement of the Comprehensive Quality of Badminton Teachers}

No matter teaching what subject, teachers play a vital role, so badminton teaching is no exception. Teachers not only need to undertake the corresponding teaching tasks, but also need to carry out scientific research in their spare time, which requires schools to be more cautious to seek for better when hiring teachers. Teachers should not be content with the status quo, but should work harder to study related professional knowledge and exchange experiences with other teachers to improve their own quality. 


\section{E. To Provide After-school Guidance of Badminton Skills to College Students}

Learning a skill not only relies on teacher's explanations and class exercises, but after-school review is also very important. Many colleges and universities launch a series of guiding measures for the situation that college students' enthusiasm for badminton learning is not high. For example, we can establish many related clubs and organizations to encourage students to participate actively. Students with the same interests and hobbies are able to get together to exchange ideas and learn from each other. Thus, more and more people are encouraged to like badminton and actively participate in badminton. Taking badminton learning as part of daily teaching and forming more active badminton learning atmosphere on campus can effectively improve students' enthusiasm for badminton learning.

\section{F. To Improve the Content of Badminton Teaching}

The purpose of badminton teaching in college is to enable students to know the relevant knowledge and basic skills of badminton and to improve the physical fitness and mental health level of college students in the actual badminton practice. Improving the content of badminton teaching will enable students to master more reasonable and systematic badminton learning methods so as to be more aware of the significance of badminton training and fall in love with the sport, so that students' learning interest can be enhanced continuously.

\section{G. To Integrate the Concept of Competition into Teaching Process}

Direct mutual cooperation and competition between people is an important path to enhance college students' badminton learning interest. As a qualified badminton teacher, necessary direct practice and interaction with classmates is dispensable. It is also possible to organize students to learn and compete with each other, and enhance students' mastery of relevant knowledge through interaction to increase their enthusiasm for participation. The competition with the principle of friendship first and competition second not only is helpful for improving students' interest in badminton, but also can inspire students' sense of collective honor and make the relationship between students more harmonious.

\section{CONClusion}

In summary, badminton learning has a very good value, so college students are very fond of this sport. However, there are indeed many factors affecting the students' badminton enthusiasm in the actual teaching of badminton in colleges and universities. This requires badminton teachers, school leaders, and students to change their own concepts, and actively improve the knowledge reserve related to badminton and practical application skills. Teachers and students should continue to improve their own quality to accept badminton with a positive attitude. Schools should pay attention to teaching students according to their aptitudes so as to create a relaxed and active badminton learning environment and eventually enhance college students' interest in badminton learning.

\section{REFERENCES}

[1] Chen Chaoxiu, Deng Chaohui. Survey and Analysis of Students' Interests and Motives in Badminton Class in colleges--A Case Study of Jiangxi Normal University. Science \& Technology Vision, 2016,16(6):158-159.

[2] Zhang Qiang. Consideration on the Influencing Factors of Students Learning in Badminton Teaching in Colleges and Universities. Sporting Goods \& Business, 2015,23(16):126-126.

[3] Zhou Min. Mobilize learning enthusiasm and carry out efficient teaching of badminton in colleges and universities. Education circle, 2016,7(25):174-174.

[4] Xin Wenjuan. Analysis of the Factors Affecting Students' Learning in Badminton Teaching. Bulletin of Sport Science \& Technology, 2015, 23(12):89-89.

[5] Liu Zhengzhi, Li Guozhong, Zhu Dan, et al. Study on the Influence of Autonomous and Cooperative Teaching Method on the Learning Motivation of Badminton Class in Colleges and Universities. Contemporary Education Research and Teaching Practice, 2015,12(5):147-148. 